\title{
Cause or Consequence? What is the Relationship between Cardiac Injury and COVID-19 Severity?
}

Claudio Tinoco Mesquita ${ }^{1,2,3}$

Universidade Federal Fluminense, ${ }^{1}$ Niterói, $R J$ - Brazil

Nuclear Medicine Department - Hospital Pró-Cardíaco, ${ }^{2}$ Rio de Janeiro, RJ - Brazil

Hospital Vitória, ${ }^{3}$ Rio de Janeiro, RJ - Brazil

Editorial referring to the article: Predictive Value of Myocardial injury in Patients with COVID-19 Admitted to a Quaternary Hospital in the City of Rio de Janeiro

"I know nothing and my heart aches"

Fernando Pessoa, The Book of Disquiet

In most patients, coronavirus disease-2019 (COVID-19) causes minor respiratory symptoms or even no symptoms. SARS-CoV-2 infection can also cause extrapulmonary manifestations and complications. COVID-19 is more severe and fatal among patients with pre-existing cardiovascular risk factors or diseases. ${ }^{1}$ Increases in cardiac troponin (cTn) are indicative of myocardial injury and frequently found in patients with COVID-19. ${ }^{2}$ The Chinese Center for Disease Control and Prevention published a survey demonstrating that among patients diagnosed with COVID-19, 13\% had hypertension, 5\% had diabetes mellitus, and $4 \%$ had a history of cardiovascular disease. However, in this same cohort, among patients who had not survived, $40 \%$ had hypertension, $20 \%$ had diabetes, and $22 \%$ had pre-existing cardiovascular disease. ${ }^{3}$ Patients with cardiovascular disease had the highest case fatality rate $(10.5 \%)$.

In this issue of the International Journal of Cardiovascular Sciences, Rocha et al. , ${ }^{4}$ studied 192 patients admitted with COVID-19 in a quaternary care cardiac hospital in Rio de Janeiro, Brazil. Mortality rate was $28 \%$. Multivariate analysis demonstrated that elevated cTnI levels (OR=9.504; 95\% CI=1.281-70.528; $\mathrm{P}=0.028$ ) upon admission and the need for mechanical ventilation

\section{Keywords}

Cardiovascular Diseases/complications; COVID-19/ complications; SARS-CoV-2; Risk Factors; Hypertension; Diabetes Mellitus; Troponin I; Hospitalization; Mortality. during hospitalization $(\mathrm{OR}=46.691 ; 95 \% \mathrm{CI}=2.360$ 923.706; $\mathrm{P}=0.012$ ) were independent predictors of death during hospitalization. ${ }^{4}$ The main limitations of the study are a sample from a single Brazilian metropolitan region and a short follow-up period. However, these limitations do not invalidate the main message of the study: the measurement of cardiac troponin at hospital admission may be useful for identification of high-risk patients infected by SARS-CoV-2.

Cardiac troponins are not specific markers of ischemic injury of the heart. The Fourth Universal Definition of Myocardial Infarction defines myocardial injury (acute or chronic) as cTn concentrations $>99$ th percentile upper reference limit (URL). While dynamic changes in cardiac troponins characterize acute injury, patients without these changes have chronic injury. ${ }^{5}$ Patients with COVID-19 have several conditions that may be associated with myocardial injury such as myocarditis, stress cardiomyopathy, acute heart failure, pulmonary embolism, critical illness, and sepsis. ${ }^{2}$ Garcia de Guadiana-Romualdo et al., ${ }^{6}$ demonstrated that elevated troponin levels were common in patients with COVID-19. These authors found abnormal levels of cTn in $26.9 \%$ of the patients and in 30\% when sex-specific cut-offs were used to detect myocardial injury. ${ }^{6}$ Some factors increase the risk of abnormal cTn levels, including older age and the type of troponin measured (troponin $\mathrm{T}$ is associated with higher levels). Nascimento et al., ${ }^{7}$ studied 61 patients admitted to intensive care unit with COVID-19 in a Brazilian hospital and found a high incidence of myocardial infarction in patients with severe COVID-19, with impact on in-hospital mortality. ${ }^{7}$

COVID-19 can damage the cardiovascular system in many ways. A myocardial oxygen supply-demand 
mismatch (type 2 myocardial infarction) can result from an imbalance between high metabolic demand and low cardiac reserve, systemic inflammation and thrombogenesis, in addition to direct cardiac damage from the virus. ${ }^{8}$ Cardiovascular complications occur mainly in patients with cardiovascular risk factors (advanced age, hypertension and diabetes) or preexisting cardiovascular diseases. There are few reports of COVID-19 patients who presented with acute ST-segment elevation myocardial infarction (STEMI) that the final diagnosis was myocarditis. This diagnosis is supported by elevated cardiac troponins, moderate decrease of left ventricular ejection fraction, and absence of flow-limiting coronary artery disease by invasive coronary angiography. ${ }^{9}$ Autopsy findings support the concept that the pathogenesis of severe COVID-19 involves a virus-induced injury of multiple organs, including heart and lungs, coupled with the consequences of a procoagulant state with coagulopathy, although overt myocarditis is very rare. ${ }^{10}$ Together, these data suggest that in most cases, myocardial injury detected by increased cardiac troponins are not causes of severe COVID-19, but rather consequences/effects of high risk COVID-19.

Type I myocardial infarction is not commonly associated with COVID-19 and some studies have shown even a decreased incidence of hospitalization for acute myocardial infarction during the Covid-19 pandemic. Solomon et al., ${ }^{11}$ reported a decrease by up to $48 \%$ in weekly rates of hospitalization for acute myocardial infarction during the COVID-19 period. ${ }^{11}$ De Filippo et al., ${ }^{12}$ found similar reductions in 15 hospitals in northern Italy. This decrease may also be associated with the anxiety and fear of catching COVID-19 in the emergency department, commonly seen among patients during the initial months of the pandemic. Consequently, parallel to this decrease in myocardial infarction hospitalizations, a transient increase in the incidence of out-of-hospital cardiac arrest (AOHCA) was observed when compared with the equivalent time period in previous years with no pandemic. ${ }^{13}$ The same trend was demonstrated in a Brazilian study by Guimarães et al., ${ }^{14}$ who found a proportional increase of $33 \%$ of home deaths in March 2020, which is when the World Health Organization declared the COVID-19 pandemic. $^{14}$ The increase of AOHCA can be linked to COVID-19 infections and to the potential increase of patients with acute cardiac diseases that did not seek emergency care.

We are entering a new phase of the COVID-19 pandemic. The United Kingdom's Medicines and Healthcare products Regulatory Agency has issued temporary authorization of the antiviral drug molnupiravir for the treatment of mild to moderate COVID-19 in adults with at least one risk factor for severe illness. ${ }^{15}$ The approval of effective oral drugs, combined with the use of effective vaccines against COVID-19, can potentially change the scenario and contribute to a consistent decrease in the number of cases and the adverse effects of SARS-COV-2 infections. ${ }^{16,17}$ However, we must remember that there is a long way to go to let our guard down. Science needs to be protected and valued; now more than ever.

\section{Sources of Funding}

Dr. Claudio Tinoco Mesquita receives funding from CNPq and FAPERJ.

\section{References}

1. Zhou F, Yu T, Du R, Fan G, Liu Y, Liu Z, et al. Clinical course and risk factors for mortality of adult inpatients with COVID-19 in Wuhan, China: a retrospective cohort study. Lancet. 2020;395(10229):1054-62. Doi:10.1016/50140-6736(20)30566-3

2. Sandoval Y, Januzzi JL, Jaffe AS. Cardiac Troponin for Assessment of Myocardial Injury in COVID-19: JACC Review Topic of the Week. J Am Coll Cardiol.2020;76(10):1244-58. Doi:10.1016/j. jacc.2020.06.068

3. Lang JP, Wang X, Moura FA, Siddiqi HK, Morrow DA, Bohula EA. A current review of COVID-19 for the cardiovascular specialist. Am Heart J. 2020 Aug; 226:29-44. Doi: 10.1016/j.ahj.2020.04.025

4. Rocha ASC da, Volschan A, Campos LAA, Coelho RP dos S, Thielmann DC de A, Ferreira CALC, et al. Predictive Value of Myocardial injury in Patients with COVID-19 Admitted to a Quaternary Hospital in the City of Rio de Janeiro. Int J Cardiovasc Sci. 2022; 35(1):58-64.

5. Thygesen K, Alpert JS, Jaffe AS, Chaitman BR, Bax JJ, Morrow DA, et al. Fourth Universal Definition of Myocardial Infarction . Circulation. 2018 Nov 13;138(20):e618-51.

6. García de Guadiana-Romualdo L, Morell-García D, Rodríguez-Fraga O, Morales-Indiano C, Padilla Jiménez MLA, Gutiérrez Revilla JI, et al. Cardiac troponin and COVID-19 severity: Results from BIOCOVID study. Eur J Clin Invest.2021;;51(6):e13532. Doi: 10.1111/eci.13532

7. Nascimento JHP, da Costa RL, Simvoulidis LFN, de Pinho JC, Pereira RS, Porto AD, et al. Covid-19 and myocardial injury in a brazilian icu: High incidence and higher risk of in-hospital mortality. Arq Bras Cardiol. 2021;116(2):275-82. Doi:10.36660/abc.20200671

8. Costa IBS da S, Bittar CS, Rizk SI, Filho AE de A, Santos KAQ, Machado TIV, et al. The heart and COVID-19: What cardiologists need to know. Arq Bras Cardiol. 2020;114(5):805-16. 
9. Loghin C, Chauhan S, Lawless SM. Pseudo-Acute Myocardial Infarction in a Young COVID-19 Patient. JACC: Case Rep. 2020;2(9):1284-8. Doi: 10.1016/j.jaccas.2020.04.015

10. Buja LM, Wolf D, Zhao B, Akkanti B, McDonald M, Lelenwa L, et al. The emerging spectrum of cardiopulmonary pathology of the coronavirus disease 2019 (COVID-19): Report of 3 autopsies from Houston, Texas, and review of autopsy findings from other United States cities. Cardiovasc Pathol. 2020;48:107233.

11. Solomon MD, McNulty EJ, Rana JS, Leong TK, Lee C, Sung S-H, et al. The Covid-19 Pandemic and the Incidence of Acute Myocardial Infarction. N Engl J Med. 2020;383(7):691-3. NEJMc2015630.

12. De Filippo O, D’Ascenzo F, Angelini F, Bocchino PP, Conrotto F, Saglietto A, et al. Reduced Rate of Hospital Admissions for ACS during Covid-19 Outbreak in Northern Italy. N Engl J Med. 2020;383(1):88-9.

13. Marijon E, Karam N, Jost D, Perrot D, Frattini B, Derkenne C, et al. Out-of-hospital cardiac arrest during the COVID-19 pandemic in Paris,
France: a population-based, observational study. Lancet Public Health. 2020;2020;5(8):e437-e443.

14. Guimarães NS, Carvalho TML, Machado-Pinto J, Lage R, Bernardes RM, Peres ASS, et al. Increased home death due to cardiopulmonary arrest in times of covid-19 pandemic. Arq Bras Cardiol. 2021;116(2):266-71.

15. Mahase E. Covid-19: UK becomes first country to authorise antiviral molnupiravir. BMJ [Internet]. 2021 Nov 4;n2697. Available from: https://www.bmj.com/lookup/doi/10.1136/bmj.n2697

16. Polack FP, Thomas SJ, Kitchin N, Absalon J, Gurtman A, Lockhart S, et al. Safety and Efficacy of the BNT162b2 mRNA Covid-19 Vaccine. N Engl J Med. 2020;383(27):2603-15. Epub 2020 Dec 10

17. Voysey M, Clemens SAC, Madhi SA, Weckx LY, Folegatti PM, Aley PK, et al. Safety and efficacy of the ChAdOx1 nCoV-19 vaccine (AZD1222) against SARS-CoV-2: an interim analysis of four randomised controlled trials in Brazil, South Africa, and the UK. Lancet.2021;397(10269):99-11. Doi: 10.1016/S 0140-6736(20)32661-1 